\title{
Aerobic training enhances muscle deoxygenation in early post-myocardial infarction
}

\author{
Shun Takagi ${ }^{1,2} \cdot$ Norio Murase $^{2} \cdot$ Ryotaro Kime $^{2} \cdot$ Masatsugu Niwayama $^{3}$. \\ Takuya Osada $^{2} \cdot$ Toshihito Katsumura $^{2}$
}

Received: 24 July 2015 / Accepted: 4 January 2016 / Published online: 12 January 2016

(c) The Author(s) 2016. This article is published with open access at Springerlink.com

\begin{abstract}
Purpose Exercise-induced skeletal muscle deoxygenation is startling by its absence in early post-myocardial infarction (MI) patients. Exercise training early post-MI is associated with reduced cardiovascular risk and increased aerobic capacity. We therefore investigated whether aerobic training could enhance the muscle deoxygenation in early post-MI patients.

Methods $21 \pm 8$ days after the first MI patients $(n=16)$ were divided into 12-week aerobic training (TR, $n=10$ ) or non-training (CON, $n=6)$ groups. Before and after intervention, patients performed ramp bicycle exercise until exhaustion. Muscle deoxygenation was measured at vastus lateralis by near-infrared spectroscopy during exercise.

Results Aerobic training significantly increased peak oxygen uptake $\left(\mathrm{VO}_{2}\right)(18.1 \pm 3.0$ vs. $22.9 \pm 2.8 \mathrm{~mL} / \mathrm{kg} / \mathrm{min})$, decreased the change in muscle oxygen saturation from rest to submaximal and peak exercise $\left(\Delta \mathrm{SmO}_{2} ; 2.4 \pm 5.7\right.$ vs. $-7.0 \pm 3.4 \%$ ), and increased the relative change in deoxygenated hemoglobin/myoglobin concentration from rest to submaximal $(-1.5 \pm 2.3$ vs. $3.0 \pm 3.6 \mu \mathrm{mol} / \mathrm{L})$ and peak exercise $(1.1 \pm 4.5$ vs. $8.2 \pm 3.5 \mu \mathrm{mol} / \mathrm{L})$. Change in
\end{abstract}

Communicated by Jean-René Lacour.

Shun Takagi

stakagi@aoni.waseda.jp

1 Faculty of Sport Sciences, Waseda University, 2-579-15 Mikajima, Tokorozawa, Saitama 359-1192, Japan

2 Department of Sports Medicine for Health Promotion, Tokyo Medical University, 6-1-1 Shinjuku, Shinjuku-ku, Tokyo 160-8402, Japan

3 Department of Electrical and Electronic Engineering, Faculty of Engineering, Shizuoka University, 3-5-1 Johoku, Naka-ku, Hamamatsu, Shizuoka 432-8561, Japan total hemoglobin/myoglobin concentration in muscle was not significantly affected by training. In CON, no significant alterations were found after 12 weeks in either muscle deoxygenation or peak $\mathrm{VO}_{2}(18.6 \pm 3.8 \mathrm{vs} .18 .9 \pm 4.6 \mathrm{~mL} /$ $\mathrm{kg} / \mathrm{min}$ ). An increase in peak $\mathrm{VO}_{2}$ was significantly negatively correlated with change in $\Delta \mathrm{SmO}_{2}(r=-0.65)$ and positively associated with change in $\Delta$ deoxy- $\mathrm{Hb} / \mathrm{Mb}$ at peak exercise $(r=0.64)$ in TR.

Conclusions In early post-MI patients, aerobic training enhanced skeletal muscle deoxygenation, and the enhancement was related to increased aerobic capacity.

Keywords Cycling training - Ischemic heart disease Microcirculation $\cdot$ Near-infrared spectroscopy $\cdot$ Oxygen transport

\begin{tabular}{|c|c|}
\hline Abbreviations & \\
\hline ANOVA & Analysis of variance \\
\hline CHF & Chronic heart failure \\
\hline $\mathrm{CON}$ & Non-training group \\
\hline Deoxy-Hb/Mb & $\begin{array}{l}\text { Deoxygenated hemoglobin/myoglobin } \\
\text { concentration }\end{array}$ \\
\hline HR & Heart rate \\
\hline LT & Lactate threshold \\
\hline LVEF & Left ventricular ejection fraction \\
\hline MI & Myocardial infarction \\
\hline MRT & Mean response time \\
\hline NIRS & Near-infrared spectroscopy \\
\hline $\mathrm{NIR}_{\text {SRS }}$ & $\begin{array}{l}\text { Near-infrared spatial resolved } \\
\text { spectroscopy }\end{array}$ \\
\hline $\mathrm{O}_{2}$ & Oxygen \\
\hline $\mathrm{Oxy}-\mathrm{Hb} / \mathrm{Mb}$ & $\begin{array}{l}\text { Oxygenated hemoglobin/myoglobin } \\
\text { concentration }\end{array}$ \\
\hline RER & Respiratory exchange ratio \\
\hline $\mathrm{SmO}_{2}$ & Muscle oxygen saturation \\
\hline
\end{tabular}




$\begin{array}{ll}\text { Total-Hb/Mb } & \begin{array}{l}\text { Total hemoglobin/myoglobin } \\ \text { concentration }\end{array} \\ \mathrm{TR} & \text { Training group } \\ \mathrm{VCO}_{2} & \text { Carbon dioxide production } \\ \mathrm{VL} & \text { Vastus lateralis } \\ \mathrm{VO}_{2} & \text { Oxygen uptake } \\ \mathrm{WR} & \text { Work rate }\end{array}$

\section{Introduction}

Exercise training after onset of heart attack is important for heart disease patients to improve aerobic capacity. In chronic heart failure (CHF) patients, an improvement of aerobic capacity by exercise training can be explained not only by increased cardiac output in the heart (Dubach et al. 1997), but also increased peak muscle blood flow (Sullivan et al. 1988), increased arterial venous oxygen $\left(\mathrm{O}_{2}\right)$ difference (Dubach et al. 1997), and increased mitochondrial density and oxidative enzyme activity in skeletal muscle (Belardinelli et al. 1995; Minotti et al. 1990; Sullivan et al. 1988). However, the ability for patients to increase peripheral variables associated with aerobic capacity by exercise training soon after myocardial infarction (MI) has not been well established. Previous studies partly demonstrated that an aerobic training intervention improved peripheral factors such as a cross-sectional area of thigh muscle (Murabayashi et al. 1997) and muscle oxidative capacity (Cottin et al. 1996) in early post-MI patients. However, these studies had no control (i.e. non-training) group. It is possible that cardiovascular responses and aerobic capacity may be gradually improved over the natural time course in early after onset of MI patients (Wohl et al. 1977). Therefore, peripheral factors and their relationship to the improvement of aerobic capacity may be altered without exercise training. To strictly test the effect of training in early post heart disease patients, the effect of the natural time course should be also investigated.

The balance between $\mathrm{O}_{2}$ delivery and utilization in exercising muscle can be measured noninvasively by nearinfrared spectroscopy (NIRS) technique during dynamic exercise (Hamaoka et al. 2007), and the technique has been widely used in the research areas of sports science and exercise physiology. Recently, Takagi et al. (2014) reported that in early post-MI patients, the absence of muscle deoxygenation measured by NIRS technique was observed during submaximal and peak exercise, and the deoxygenation abnormalities were related to reduced systemic aerobic capacity. To date, it is unclear whether aerobic exercise training improves skeletal muscle deoxygenation abnormalities in early post-MI patients. In addition, changes in muscle deoxygenation through exercise training might be related to improvement of peak aerobic capacity, if exercise training alters muscle deoxygenation. An increase in aerobic capacity reduces cardiovascular-associated morbidity and mortality, as well as an increase in physical activity (Myers et al. 2004). Therefore, an increase in peak aerobic capacity via exercise training is important even for early post-MI patients. Moreover, early initiation of moderate intensity aerobic training may be more beneficial to improve peak aerobic capacity than late initiation (Johnson et al. 2014). Assessing the effects of aerobic training on muscle deoxygenation can be useful and helpful in understanding the increase in peripheral variables and its relation to increased peak aerobic capacity in MI patients. The aim of this study was to investigate the effects of aerobic exercise training on muscle deoxygenation and its relationship to aerobic capacity.

\section{Methods}

\section{Patients}

Inclusion criteria of the subjects were: (1) fewer than 6 weeks after onset of their first heart attack, (2) age between 40 and 75 years old, and (3) ability to perform exercise testing. All participants had received a percutaneous coronary stent as part of their post-MI clinical treatment. Initially, 23 MI patients were recruited between June 2010 and March 2012 from the cardiac rehabilitation center at Tokyo Medical University Hospital. Patients with peripheral vascular disease, post-infarction angina, critical arrhythmia, (unstable) heart failure, or lung disease were excluded. As a result, 16 early post-MI patients ( $21 \pm 8$ days after the first MI) were chosen to participate and invited to engage in exercise training. However, 6 of the 16 subjects were unable to participate in exercise training due to their work schedules. The authors decided to exclude them from the training group, and consequently, the 16 MI subjects were divided into an aerobic exercise training (TR, $n=10)$ group and a non-training ( $\mathrm{CON}, n=6)$ group (Table 1). Mean left ventricular ejection fraction (LVEF) was determined by echocardiography. Peak creatine kinase was measured during the course of their disease. Hemoglobin concentration was measured before exercise testing by blood sampling from the antecubital vein. All medication dosages taken by the MI patients remained stable during the study. Before this study, all patients participated in approximately five sessions of exercise training as part of cardiac rehabilitation in the hospital. A session consisted of cycling exercise for $30 \mathrm{~min}$ at the individual's three metabolic equivalents. The study protocol was approved by the Medical Research Ethics Committee of Tokyo Medical 
Table 1 Physical and clinical characteristics and medication profiles

\begin{tabular}{|c|c|c|c|c|}
\hline & \multicolumn{2}{|l|}{$\mathrm{TR}(n=10)$} & \multicolumn{2}{|l|}{$\operatorname{CON}(n=6)$} \\
\hline & Before & After & Before & After \\
\hline Age (years) & $59 \pm 10$ & NA & $61 \pm 9$ & NA \\
\hline Height $(\mathrm{cm})$ & $164.9 \pm 9.6$ & NA & $165.5 \pm 7.2$ & NA \\
\hline Weight (kg) & $68.5 \pm 13.9$ & $68.8 \pm 13.7$ & $65.9 \pm 12.2$ & $66.1 \pm 12.0$ \\
\hline Men/women & $8 / 2$ & - & $5 / 1$ & - \\
\hline Hemoglobin $\left(\mathrm{g} \mathrm{dL}^{-1}\right)$ & $13.1 \pm 1.8$ & $13.9 \pm 1.5$ & $13.5 \pm 1.6$ & $13.8 \pm 1.1$ \\
\hline Number of days after onset of MI & $20 \pm 7$ & NA & $23 \pm 8$ & NA \\
\hline $\operatorname{LVEF}(\%)$ & $56 \pm 6$ & $55 \pm 4$ & $55 \pm 9$ & $55 \pm 9$ \\
\hline Fat layer thickness at VL (mm) & $4.86 \pm 1.52$ & $4.90 \pm 1.39$ & $4.57 \pm 0.60$ & $4.55 \pm 0.57$ \\
\hline Peak creatine kinase $\left(\mathrm{IU} \mathrm{L}^{-1}\right)$ & $3674 \pm 1472$ & NA & $3084 \pm 2544$ & NA \\
\hline \multicolumn{5}{|l|}{ Site of MI (\%) } \\
\hline Anterior & 60 & NA & 67 & NA \\
\hline Inferior & 40 & NA & 33 & NA \\
\hline \multicolumn{5}{|l|}{ Number of diseased vessels (\%) } \\
\hline 1 & 60 & NA & 67 & NA \\
\hline 2 & 20 & NA & 17 & NA \\
\hline 3 & 20 & NA & 17 & NA \\
\hline \multicolumn{5}{|l|}{ Medication (\%) } \\
\hline ACE inhibitor & 70 & - & 57 & - \\
\hline Angiotensin II receptor antagonist & 20 & - & 14 & - \\
\hline Beta-blockers & 80 & - & 71 & - \\
\hline Calcium channel antagonist & 30 & - & 29 & \\
\hline Diuretics & 30 & - & 29 & \\
\hline Diabetes $(\%)$ & 10 & - & 14 & - \\
\hline Dyslipidemia (\%) & 70 & - & 71 & - \\
\hline Hypertension (\%) & 10 & - & 14 & - \\
\hline
\end{tabular}

$T R$ training group, $C O N$ non-training group, $L V E F$ left ventricular ejection fraction, $V L$ vastus lateralis, $M I$ myocardial infarction, $A C E$ angiotensin converting enzyme, $N A$ not available, - no change between before and after intervention
University (\#1405) and was conducted in accordance with the Declaration of Helsinki. All subjects were informed of the purpose of the study, and written informed consent was obtained.

\section{Exercise training}

Training frequency was set to two sessions per week for 12 weeks. Each session mainly consisted of cycling exercise for $30 \mathrm{~min}$ at the individual's estimated lactate threshold (LT) minus $10 \mathrm{~W}$. Before and after the main cycling exercise, subjects performed stretching for $10 \mathrm{~min}$ and cycling at a half of LT minus $10 \mathrm{~W}$ for $1 \mathrm{~min}$, as a warm up and cool down. The intensity of cycling training was increased gradually $(5 \mathrm{~W})$ over the training period if the heart rate (HR) of estimated LT level attained during baseline exercise testing was not attained during training. All training was monitored by physicians. In $\mathrm{CON}$, none of the subjects were involved in any type of exercise training over the 12 weeks.

\section{Exercise testing (aerobic capacity and cardiorespiratory variables measurement)}

In both groups, exercise testing was administered before and after 12 weeks to evaluate the effects of training. After a 3-min warm up at $10 \mathrm{~W}$, the subjects performed $10 \mathrm{~W} \mathrm{~min}^{-1}$ ramp cycling exercise until exhaustion (Strength Ergo 8, Fukuda-Denshi, Japan). During exercise, pedal frequency of $50 \mathrm{rpm}$ was maintained by keeping time with a metronome, as used in previous studies (Takagi et al. 2014). Subjects were supervised by the investigators, and verbal encouragement was given when needed. All subjects exercised until they could no longer sustain the required cadence. The HR was monitored continuously during the exercise by a 12-lead electrocardiogram (ML-9000 Stress Test System; Fukuda-Denshi, Japan), and pulmonary $\mathrm{O}_{2}$ uptake $\left(\mathrm{VO}_{2}\right)$ and carbon dioxide production $\left(\mathrm{VCO}_{2}\right)$ were assessed breath-by-breath (AE310S; Minato Medical Science, Japan) to determine peak $\mathrm{VO}_{2}$ and estimated LT, using the $\mathrm{V}$-slope method and substantiated in the profiles 
of the end-tidal partial pressures of $\mathrm{O}_{2}$ and $\mathrm{CO}_{2}$, the ventilatory equivalents for $\mathrm{VO}_{2}$ and $\mathrm{VCO}_{2}$, and respiratory exchange ratio (RER) (Beaver et al. 1986; Takagi et al. 2014; Wasserman et al. 1973). Immediately after maximal exercise, all subjects cycled at $10 \mathrm{~W}$ for $3 \mathrm{~min}$. The seat and handlebar height remained constant for each subject in exercise testing before and after training.

\section{$\mathrm{VO}_{2}$ response}

The $\Delta \mathrm{VO}_{2} / \Delta \mathrm{WR}$ slope during ramp exercise was calculated by the linear regression of $\mathrm{VO}_{2}$ with work rate, from 4 min after the beginning of the ramp loading up to the point that represented $80 \%$ of the total duration of ramp exercise (Boone et al. 2008; Day et al. 2003). Ideally, the sub-LT region of the response should have been analyzed, however, since the fit was based on only a very small amount of data, it would have become unstable in the $\Delta \mathrm{VO}_{2} / \Delta \mathrm{WR}$ slope. The mean response time (MRT) in $\mathrm{VO}_{2}$ during ramp exercise was calculated as the time from onset of the ramp workload to the point of intersection between the baseline $\mathrm{VO}_{2}$ during warm up and a backward extrapolation of the $\mathrm{VO}_{2}$ vs time slope (Boone et al. 2008; Takagi et al. 2014). The baseline $\mathrm{VO}_{2}$ was defined as the mean of $\mathrm{VO}_{2}$ during the last 2 min of warm up. For some subjects, workloads 4 min after onset of ramp loading were higher than workloads at estimated LT. Therefore, the whole slope of $\Delta \mathrm{VO}_{2} / \Delta \mathrm{WR}$ and the MRT were calculated using data from six MI patients in TR and four MI patients in CON.

\section{Skeletal muscle deoxygenation measurements}

Relative changes from rest in oxygenated hemoglobin/ myoglobin concentration ( $\Delta \mathrm{oxy}-\mathrm{Hb} / \mathrm{Mb})$, deoxygenated hemoglobin/myoglobin concentration $(\Delta$ deoxy-Hb/Mb) and total hemoglobin/myoglobin concentration $(\Delta$ total- $\mathrm{Hb} /$ $\mathrm{Mb}$ ), and muscle $\mathrm{O}_{2}$ saturation $\left(\mathrm{SmO}_{2}\right)$ were continuously assessed at the belly of the vastus lateralis (VL) muscle in the left leg by near-infrared spatial resolved spectroscopy $\left(\mathrm{NIR}_{\mathrm{SRS}}\right)$. The measurement site in VL was defined as $30 \%$ of the length between the patella and the greater trochanter, above the patella (Takagi et al. 2013, 2014). The measured signals were defined as the values averaged over the last $10 \mathrm{~s}$ at rest, every $20 \mathrm{~W}$, and peak exercise. During the recovery time of re-saturation, the half-recovery time of $\mathrm{SmO}_{2}$ (T1/2reoxy) was determined as the time for $50 \%$ reoxygenation of $\mathrm{SmO}_{2}$ from the exhaustion level to the peak level (Ichimura et al. 2006). During rest periods without pedaling, subjects sat on the bicycle with the left foot on the pedal, at the lowest position.

In this study, a two-wavelength $(770$ and $830 \mathrm{~nm})$ light-

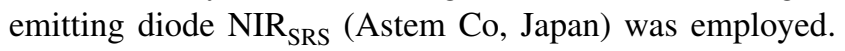

The probe consisted of one light source and two photodiode detectors, and the optode distances were 20 and $30 \mathrm{~mm}$, as were used in previous studies for measuring muscle deoxygenation (Kime et al. 2010; Takagi et al. 2014). The data sampling rate was $1 \mathrm{~Hz}$. Although a previous study demonstrated that fat layer thickness influences NIRS data due to light scattering, the effects of fat layer thickness can be corrected in relative changes in $\mathrm{Hb} / \mathrm{Mb}$ (Niwayama et al. 2000) or $\mathrm{SmO}_{2}$ (Niwayama et al. 2007). The specifications of correction for the influence of fat layer thickness have been fully described (Niwayama et al. 2000, 2007). In this study, fat layer thickness at the measurement site of the VL muscles was measured individually before and after intervention, using an ultrasound device (LogiQ3, GE-Yokokawa Medical Systems, Japan). Subsequently, we utilized an NIRS device which had built-in fat-correction software (Astem Co, Japan) and calculated relative changes in $\mathrm{Hb} / \mathrm{Mb}$ and $\mathrm{SmO}_{2}$ with correction for the influence of fat layer thickness, based on individual value of fat layer thickness before and after intervention. Even though an upper limit of fat layer thickness was designated as $10 \mathrm{~mm}$ to correct for the light-scattering effects in this study, fat layer thickness at the measurement site was within $\sim 10 \mathrm{~mm}$ in all subjects before and after intervention (Table 1).

\section{Statistical analysis}

All data are given as mean \pm standard deviation. Differences in NIRS, power output, cardiorespiratory variables at peak exercise and estimated $\mathrm{LT}, \mathrm{VO}_{2}$ response, T1/2reoxy, and demographics variables were analyzed by 2-way repeated-measures analysis of variance (ANOVA) with group and intervention (before-after) as factors. To compare changes in variables during submaximal exercise between before and after intervention over power output and percent of peak $\mathrm{VO}_{2}, 2$-way ANOVA was used, with intervention (before-after) and power output and percent of peak $\mathrm{VO}_{2}$ as factors. Because one subject could not exercise at more than $62 \mathrm{~W}$ before training and $65 \mathrm{~W}$ after training, repeated measures between groups were limited to rest, 20, 40, and $60 \mathrm{~W}$ compared as a function of power output. As a function of percent of peak $\mathrm{VO}_{2}$, differences between groups were determined at rest, 20, 40, 60 , and $80 \%$ of peak $\mathrm{VO}_{2}$. Similarly, 2-way ANOVA was also adapted to test the baseline condition between groups. Where appropriate, the Bonferroni post hoc test was performed to determine specific significant differences. Pearson's correlation coefficient was employed to determine the relationship between variables. The ANOVA and correlation coefficient were analyzed by SPSS version 17.0 J (SPSS Inc., Chicago, IL). For all statistical analyses, significance was accepted at $p<0.05$. 


\section{Results}

\section{Exercise training in TR}

Although training frequency was set at two exercise sessions/week for 12 weeks, the subjects exercised $20 \pm 3$ sessions during the 12-week training period, as their schedules permitted. Initial training intensity (i.e. estimated LT minus $10 \mathrm{~W}$ ) determined by exercise testing before training was $42 \pm 11 \mathrm{~W}$, and the final training intensity was $51 \pm 9 \mathrm{~W}$.

\section{Physical and clinical variables (Table 1)}

There were no significant interactions or significant main effects in any physical or clinical variables between before and after the intervention.

\section{Cardiorespiratory variables}

During submaximal exercise, in TR, there were significant intervention (before-after) $\times$ power output interactions for changes in $\mathrm{VO}_{2}\left(p<0.05\right.$, Fig. 1a) and $\mathrm{O}_{2}$ pulse $(p<0.05$, Fig. 1c). Even though no significant interactions were observed, a significant main effect of intervention was observed in HR $(p<0.05$, Fig. 1b) and RER $(p<0.05$, Fig. 1d). $\mathrm{VO}_{2}$ was significantly higher after training at 20-60 W, and $\mathrm{O}_{2}$ pulse was significantly greater after training at rest and 20-60 W. When expressed as a function of peak $\mathrm{VO}_{2}$ (i.e. percent of peak $\mathrm{VO}_{2}$ ), there were significant interactions for changes in $\mathrm{VO}_{2}(p<0.01)$ and $\mathrm{O}_{2}$ pulse $(p<0.01)$ in TR. Significantly higher $\mathrm{VO}_{2}$ and $\mathrm{O}_{2}$ pulse were also observed during submaximal exercise after intervention in TR. In contrast, there were no significant interactions or significant main effects in HR and RER during submaximal exercise. In CON, both expressed as a function of power output and a function of peak $\mathrm{VO}_{2}$, no significant changes were found after intervention in any cardiorespiratory variables. Moreover, at baseline, no significant difference was observed between groups in any cardiorespiratory variables during submaximal exercise.

At peak exercise, there were significant group $\times$ intervention (before-after) interactions for $\mathrm{VO}_{2}(p<0.01), \mathrm{O}_{2}$ pulse $(p<0.05)$, and power output $(p<0.05)$. In TR, peak $\mathrm{VO}_{2}(p<0.01), \mathrm{O}_{2}$ pulse at peak exercise $(p<0.01)$, and peak power output $(p<0.01)$ were significantly increased by training compared to before training (Fig. 1a, c; Table 2), and peak $\mathrm{VO}_{2}$ was significantly higher in TR than CON after training $(p<0.05$, Table 2$)$. In contrast, there were no significant interactions or main effects in HR and RER at peak exercise. At estimated LT, there were significant group $\times$ intervention (before-after) interactions for $\mathrm{VO}_{2}(p<0.05)$ and power output $(p<0.05)$. In TR, both
$\mathrm{VO}_{2}$ and power output were significantly increased after training $(p<0.01)$ at estimated LT (Table 2).

There was a significant group $\times$ intervention (before-after) interaction for MRT $(p<0.05)$ but not for $\Delta \mathrm{VO}_{2} / \Delta$ WR slope $(p=0.80)$. The MRT was significantly lower after training than before in TR $(p<0.01)$, and the MRT tended to be lower in TR than CON after training $(p=0.09$, Table 2$)$. No significant main effects were found in $\Delta \mathrm{VO}_{2} / \Delta \mathrm{WR}$ slope.

\section{Muscle deoxygenation}

Figure 2 shows an example trace of the changes in NIRS variables in real time as the exercise proceeds, with and without fat correction. With fat correction, responses in NIRS variables were somewhat enhanced. Even though $\mathrm{SmO}_{2}$ was increased by fat correction, $\mathrm{SmO}_{2}$ responses were similar between with and without fat correction in this study.

During submaximal exercise, in TR, there were significant intervention (before-after) $\times$ power output interactions for change in $\mathrm{SmO}_{2}(p<0.01$, Fig. 3a) and $\Delta$ deoxy$\mathrm{Hb} / \mathrm{Mb}(p<0.01$, Fig. $3 \mathrm{c})$, but not in $\Delta$ oxy $-\mathrm{Hb} / \mathrm{Mb}$ $(p=0.21$, Fig. $3 b)$ or $\Delta$ total-Hb/Mb $(p=0.32$, Fig. $3 \mathrm{~d})$. Moreover, no significant main effect for training was observed in $\Delta$ oxy- $\mathrm{Hb} / \mathrm{Mb}(p=0.18)$ or $\Delta$ total- $\mathrm{Hb} / \mathrm{Mb}$ $(p=0.54)$ in TR. After training, $\mathrm{SmO}_{2}$ was significantly decreased at 40-60 W $(p<0.01)$ compared to before training. Similarly, $\Delta$ deoxy-Hb/Mb was significantly increased after training compared to before at $40-60 \mathrm{~W}(p<0.01)$. We also found significant interactions for changes in $\mathrm{SmO}_{2}$ $(p<0.01)$ and $\Delta$ deoxy-Hb/Mb $(p<0.01)$ in TR when NIRS data was expressed as a function of peak $\mathrm{VO}_{2}$, and significantly lower $\mathrm{SmO}_{2}$ and higher deoxy- $\mathrm{Hb} / \mathrm{Mb}$ were obtained during submaximal (40-80\% of peak $\mathrm{VO}_{2}$ ) exercise after intervention in TR. There were no significant interactions or main effects of intervention in $\Delta \mathrm{oxy}-\mathrm{Hb} /$ $\mathrm{Mb}$ and $\Delta$ total- $\mathrm{Hb} / \mathrm{Mb}$ as a function of peak $\mathrm{VO}_{2}$. In $\mathrm{CON}$, both expressed as a function of power output and a function of peak $\mathrm{VO}_{2}$, there were no significant changes after 12 weeks in any NIRS variables. At baseline, no significant differences were found in these variables between TR and CON during submaximal exercise.

At peak exercise, there were significant group $\times$ intervention (before-after) interactions for $\mathrm{SmO}_{2}(p<0.05)$ and $\Delta$ deoxy- $\mathrm{Hb} / \mathrm{Mb}(p<0.05)$, while no significant interactions or main effect were observed in $\Delta$ oxy-Hb/Mb and $\Delta$ total$\mathrm{Hb} / \mathrm{Mb} . \mathrm{SmO}_{2}$ at peak exercise was significantly decreased after training than before training in TR ( $p<0.01$, Fig. 3a), and consequently, lower $\mathrm{SmO}_{2}$ was found in TR than CON after training $(p<0.05)$. Similarly, $\Delta$ deoxy- $\mathrm{Hb} / \mathrm{Mb}$ at peak exercise was significantly higher after training than before in TR $(p<0.01$, Fig. 3c) and after in CON $(p<0.05)$. 
Fig. 1 Cardiorespiratory responses in TR and CON. Change in oxygen uptake $\left(\mathrm{VO}_{2}\right.$ : a), heart rate (HR: b), oxygen pulse (c), and respiratory exchange ratio (RER: d) during ramp cycling exercise expressed as a function of power output before (closed circles) and after (open circles) intervention in exercise training (TR) and non-training groups $(\mathrm{CON})$. Significant difference between before and after intervention during submaximal exercise $(* p<0.05, * * p<0.01)$. Significant difference between before and after intervention at peak exercise $\left({ }^{\dagger} p<0.05,{ }^{\dagger \dagger} p<0.01\right)$. Significant intervention (beforeafter) $\times$ power output interaction $\left({ }^{\#} p<0.05\right)$. Significant main effects of TR $\left({ }^{\ddagger} p<0.05\right)$. For the sake of clarity, symbols indicating a significant difference between power output before and after intervention have been omitted

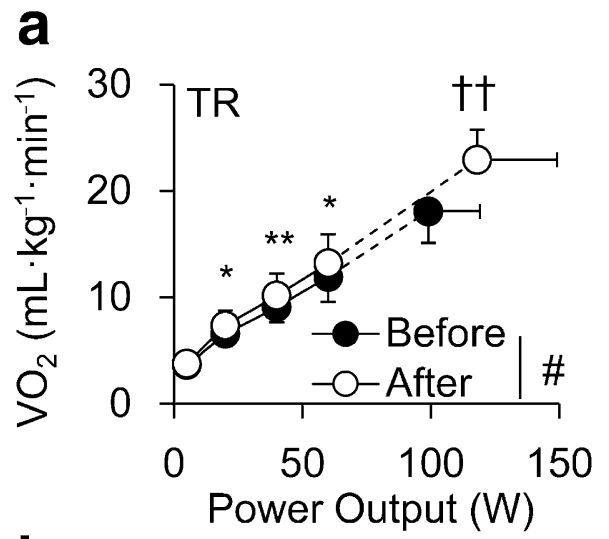

e
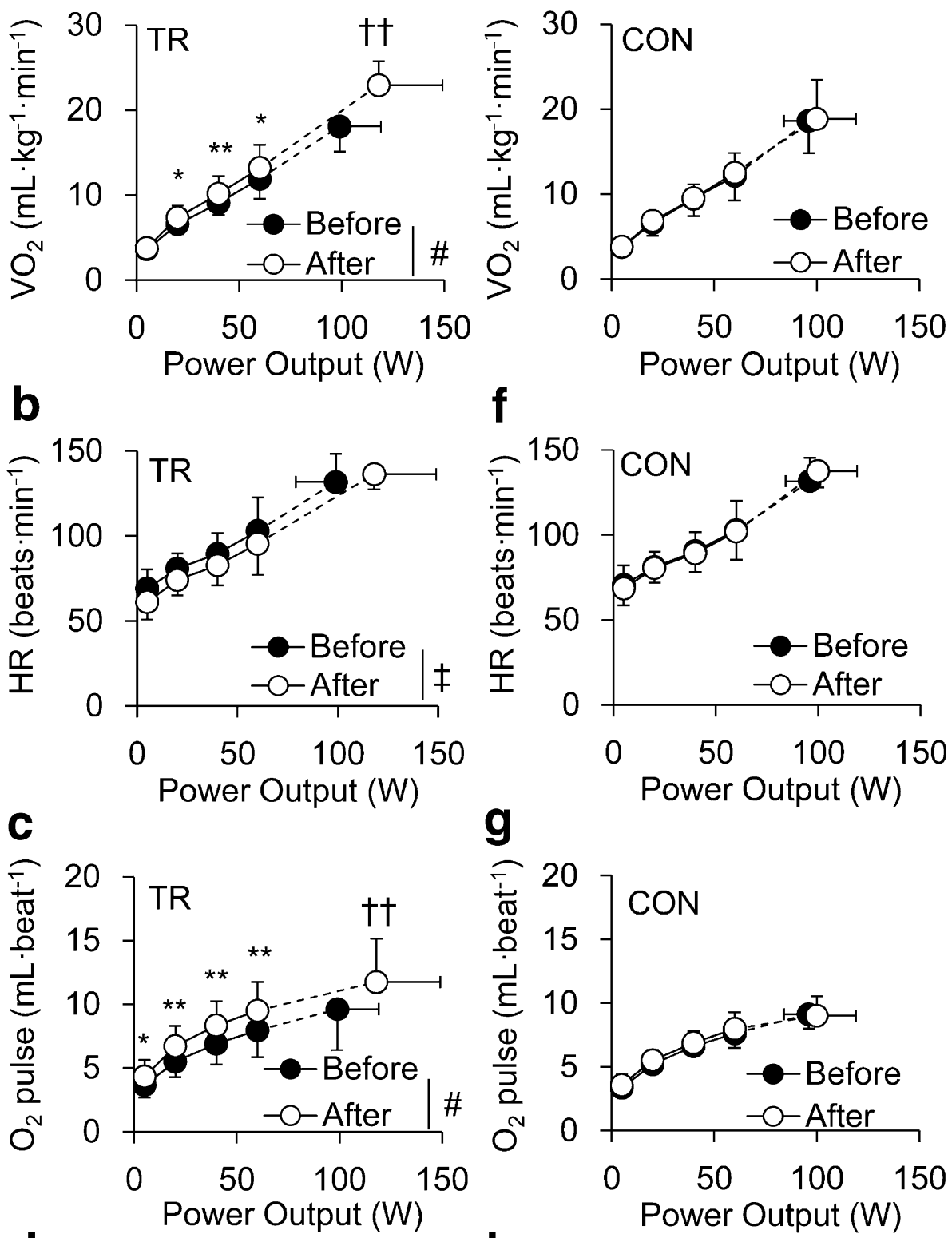

d

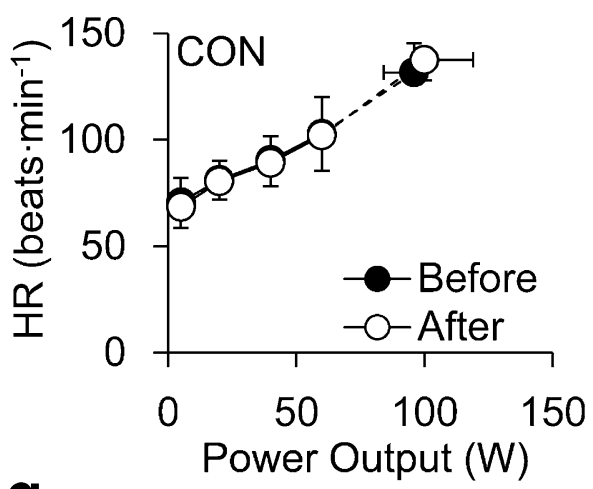

g
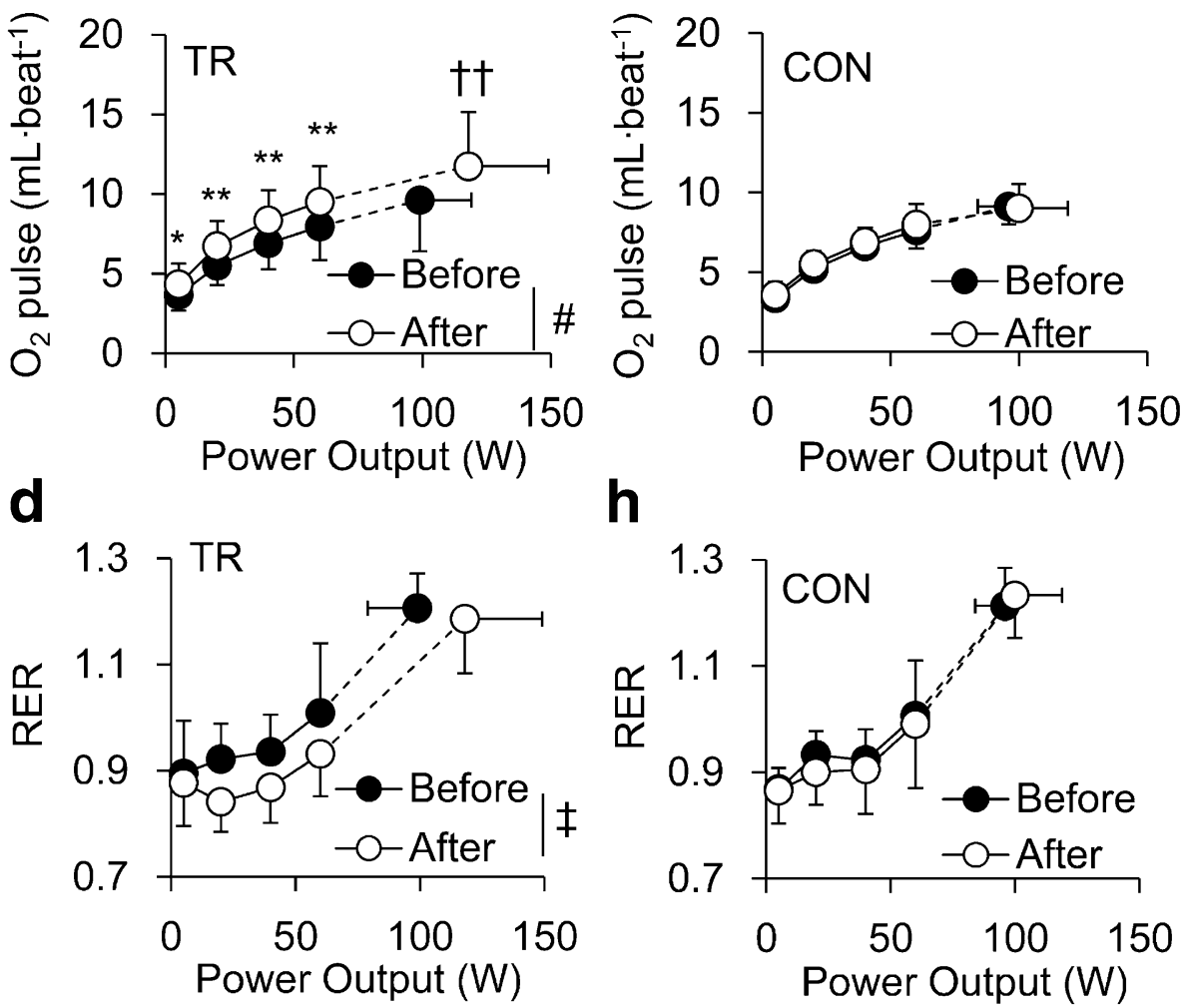

h

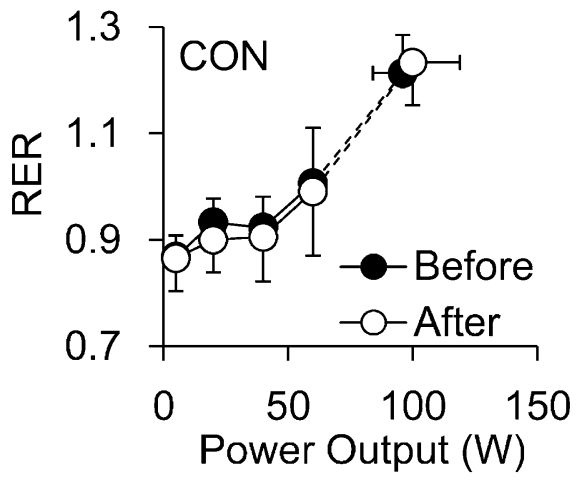


Table 2 Aerobic capacity and $\mathrm{VO}_{2}$ response during ramp exercise
Fig. 2 An example trace of the changes in NIRS variables in real time as the exercise proceeds. Changes in muscle oxygen saturation $\left(\mathrm{SmO}_{2}\right.$ : a), oxygenated hemoglobin/ myoglobin (oxy-Hb/Mb: b), deoxygenated hemoglobin/myoglobin (deoxy-Hb/Mb: c), and total hemoglobin/myoglobin (total-Hb/Mb: d) in the vastus lateralis muscle during exercise testing expressed as a function of time (s) with (solid lines) and without fat correction (dashed lines). The figures show an example trace when fat layer thickness is $6.15 \mathrm{~mm}$. Exercise testing consisted of 1 min rest, 3 min warm up, ramp exercise until exhaustion, and $3 \mathrm{~min}$ recovery

\begin{tabular}{|c|c|c|c|c|}
\hline & \multicolumn{2}{|l|}{$\mathrm{TR}(n=10)$} & \multicolumn{2}{|c|}{$\mathrm{CON}(n=6)$} \\
\hline & Before & After & Before & After \\
\hline \multicolumn{5}{|l|}{ Peak } \\
\hline $\mathrm{VO}_{2}(\mathrm{~mL} / \mathrm{kg} / \mathrm{min})$ & $18.1 \pm 3.0$ & $22.9 \pm 2.8^{* *, \#}$ & $18.6 \pm 3.8$ & $18.9 \pm 4.6$ \\
\hline Power Output (W) & $99 \pm 20$ & $119 \pm 32 * *$ & $96 \pm 12$ & $100 \pm 19$ \\
\hline Heart rate (bpm) & $132 \pm 16$ & $136 \pm 9$ & $132 \pm 14$ & $138 \pm 10$ \\
\hline \multicolumn{5}{|l|}{ Estimated LT } \\
\hline $\mathrm{VO}_{2}(\mathrm{~mL} / \mathrm{kg} / \mathrm{min})$ & $11.6 \pm 1.6$ & $14.4 \pm 2.4 * *$ & $11.9 \pm 4.0$ & $12.1 \pm 3.6$ \\
\hline Power Output (W) & $52 \pm 11$ & $63 \pm 16^{* *}$ & $52 \pm 11$ & $53 \pm 11$ \\
\hline \multicolumn{5}{|l|}{$\mathrm{VO}_{2}$ response } \\
\hline$\Delta \mathrm{VO}_{2} / \Delta \mathrm{WR}$ slope & $10.3 \pm 0.4$ & $10.3 \pm 1.0$ & $10.8 \pm 2.0$ & $10.6 \pm 0.6$ \\
\hline Mean response time in $\mathrm{VO}_{2}(\mathrm{~s})$ & $83 \pm 14$ & $61 \pm 13 * *$ & $80 \pm 27$ & $79 \pm 20$ \\
\hline $\mathrm{T} 1 / 2$ reoxy (s) & $31 \pm 5$ & $31 \pm 5$ & $32 \pm 12$ & $30 \pm 10$ \\
\hline
\end{tabular}

Significant difference between before and after intervention $(* p<0.05, * * p<0.01)$

Significant difference between TR and CON $\left({ }^{\#} p<0.05\right)$

$T R$ training group, $C O N$ non-training group, $V_{2}$ oxygen uptake, $L T$ lactate threshold, $W R$ work rate, T1/2reoxy half-recovery time of muscle oxygen saturation
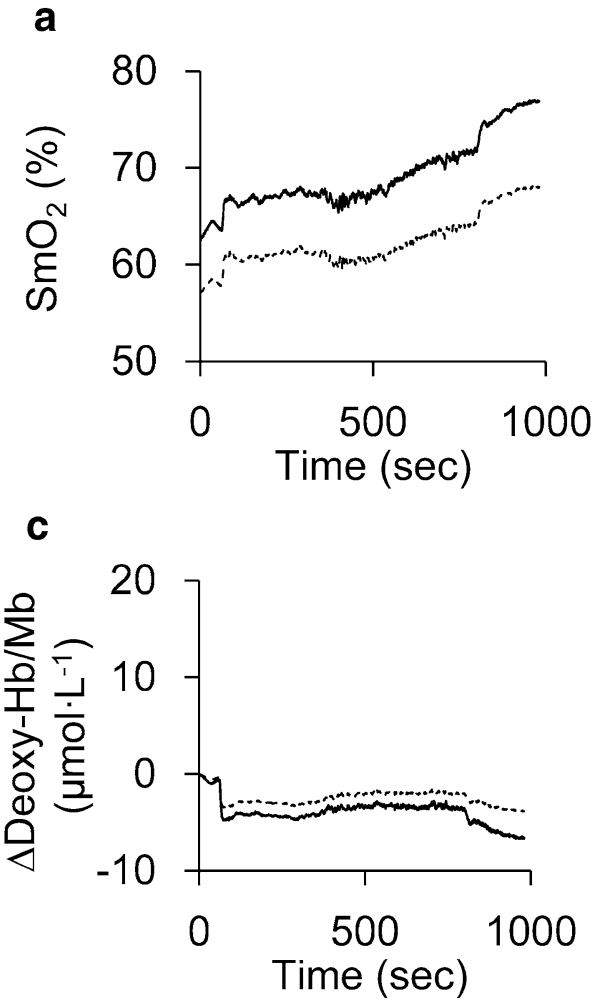

b

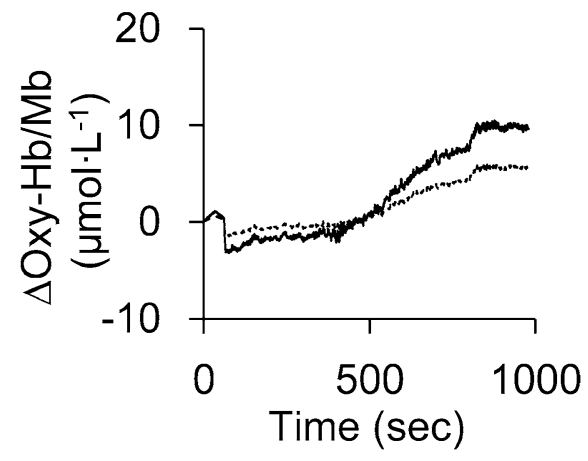

d

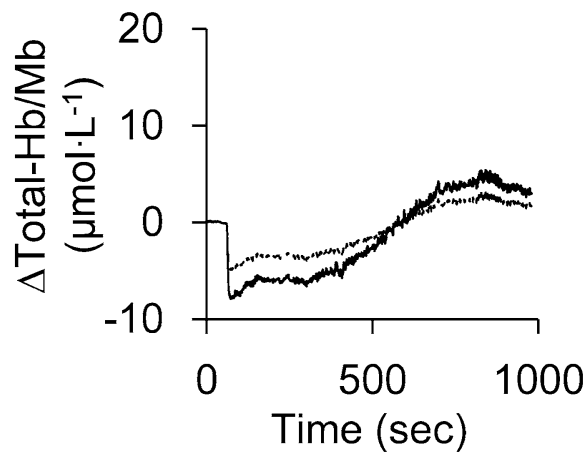

A significant group $\times$ intervention (before-after) interaction for $\Delta \mathrm{SmO}_{2}\left(\mathrm{SmO}_{2}\right.$ at peak exercise minus $\mathrm{SmO}_{2}$ at rest) was found. $\Delta \mathrm{SmO}_{2}$ was significantly decreased after training in TR (before: $2.4 \pm 5.7 \%$, after: $-7.0 \pm 3.4 \%, p<0.01)$ and after intervention in CON (TR: $-7.0 \pm 3.4 \%$, CON: $1.1 \pm 3.6 \%, p<0.01$ ). There was no significant interaction or main effect in T1/2reoxy (Table 2).

When NIRS variables are expressed without fat correction, similar changes were obtained in all variables. In TR, there were significant interactions for changes in $\mathrm{SmO}_{2}$ $(p<0.01)$ and $\Delta$ deoxy- $\mathrm{Hb} / \mathrm{Mb}(p<0.01)$, and significantly 
Fig. 3 Muscle deoxygenation in TR and CON. Change in muscle oxygen saturation $\left(\mathrm{SmO}_{2}: \mathbf{a}\right)$, oxygenated hemoglobin/myoglobin (oxy-Hb/Mb: b), deoxygenated hemoglobin/ myoglobin (deoxy-Hb/Mb: c), and total hemoglobin/myoglobin (total-Hb/Mb: d) in vastus lateralis muscle during ramp cycling exercise expressed as a function of power output intensity before (closed circles) and after (open circles) intervention in exercise training (TR) and non-training groups $(\mathrm{CON})$. Significant difference between before and after intervention during submaximal exercise $\left(* p<0.05,{ }^{*} p<0.01\right)$. Significant difference between before and after intervention at peak exercise $\left({ }^{\dagger} p<0.05,{ }^{\dagger \dagger} p<0.01\right)$. Significant intervention (beforeafter) $\times$ power output interaction $\left({ }^{\# \# p} p<0.01\right)$. For the sake of clarity, symbols indicating a significant difference between power output before and after intervention have been omitted
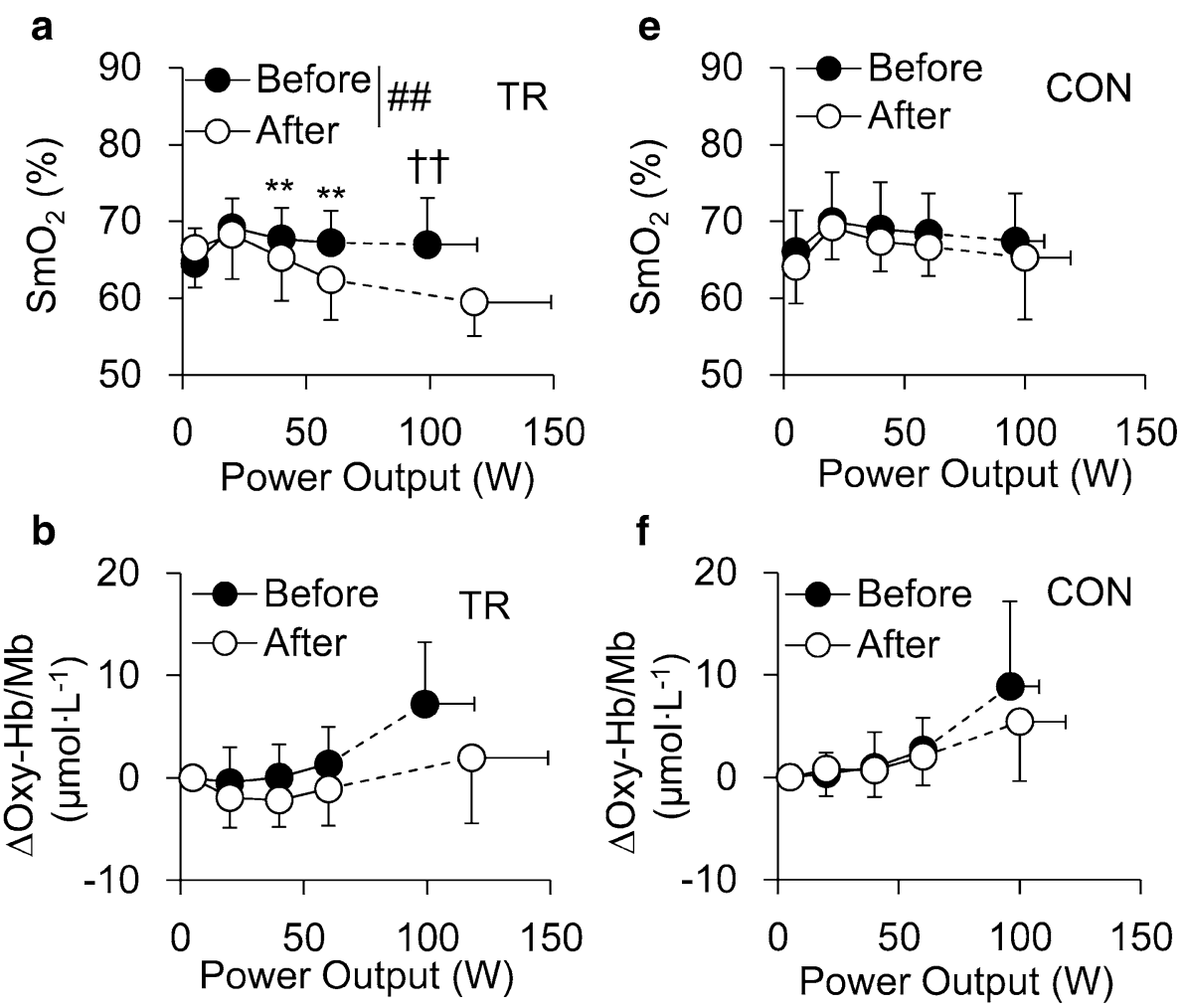

C

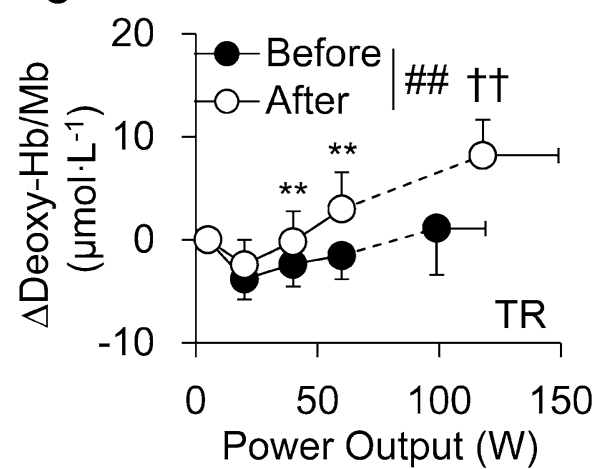

g

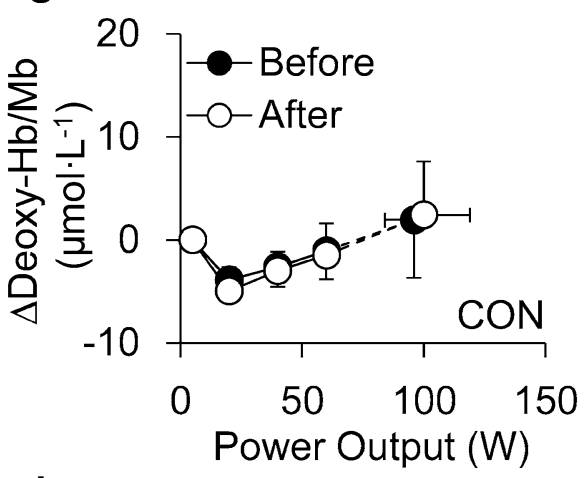

d

h

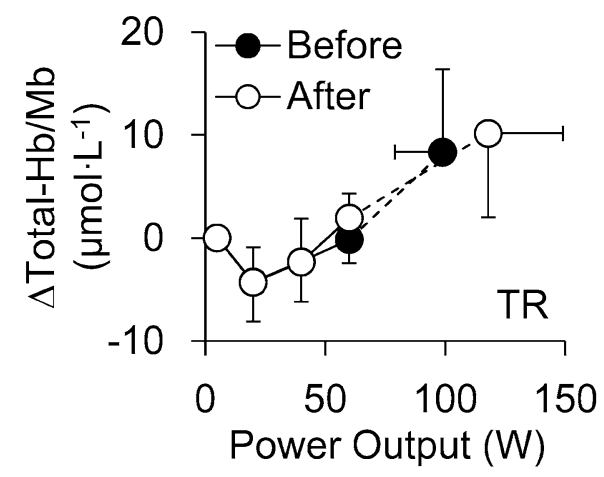

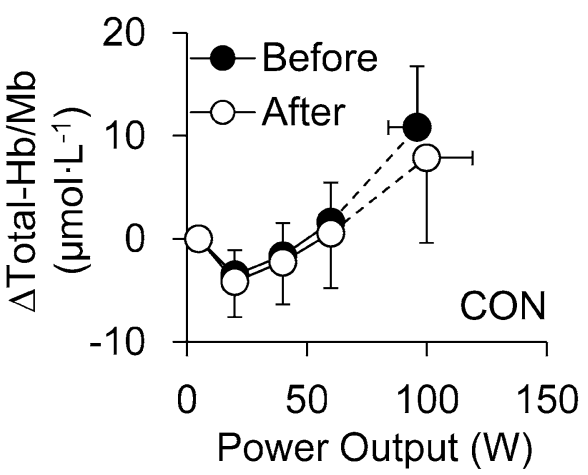

lower $\mathrm{SmO}_{2}$ and higher deoxy-Hb/Mb were observed during submaximal exercise $(40$ and $60 \mathrm{~W})$ after training. There were no significant interactions or main effects of intervention in oxy- $\mathrm{Hb} / \mathrm{Mb}$ and total- $\mathrm{Hb} / \mathrm{Mb}$. In $\mathrm{CON}$, no significant interactions or main effects of intervention were found in any NIRS variables without fat correction. 
Fig. 4 Relationship between muscle deoxygenation and aerobic capacity. Relationship between change in muscle deoxygenation by intervention and change in aerobic capacity by intervention in TR (closed circles) and $\mathrm{CON}$ (open circles). a Change in $\Delta \mathrm{SmO}_{2}\left(\Delta \mathrm{SmO}_{2}\right.$ after intervention minus $\Delta \mathrm{SmO}_{2}$ before intervention) and change in peak $\mathrm{VO}_{2}$ (peak $\mathrm{VO}_{2}$ after intervention minus peak $\mathrm{VO}_{2}$ before intervention), b change in $\Delta \mathrm{SmO}_{2}$ and change in estimated LT (estimated LT after intervention minus estimated LT before intervention), c change in $\Delta$ deoxy- $\mathrm{Hb} / \mathrm{Mb}$ at peak exercise $(\Delta$ deoxy- $\mathrm{Hb} / \mathrm{Mb}$ at peak exercise after intervention minus $\Delta$ deoxy- $\mathrm{Hb} / \mathrm{Mb}$ at peak exercise before intervention) and change in peak $\mathrm{VO}_{2}$, d change in $\Delta$ deoxy- $\mathrm{Hb} / \mathrm{Mb}$ at peak exercise and change in estimated LT. $\triangle \mathrm{SmO}_{2} \mathrm{SmO}_{2}$ at peak exercise minus $\mathrm{SmO}_{2}$ at rest, $V \mathrm{O}_{2}$ oxygen uptake, $L T$ lactate threshold a

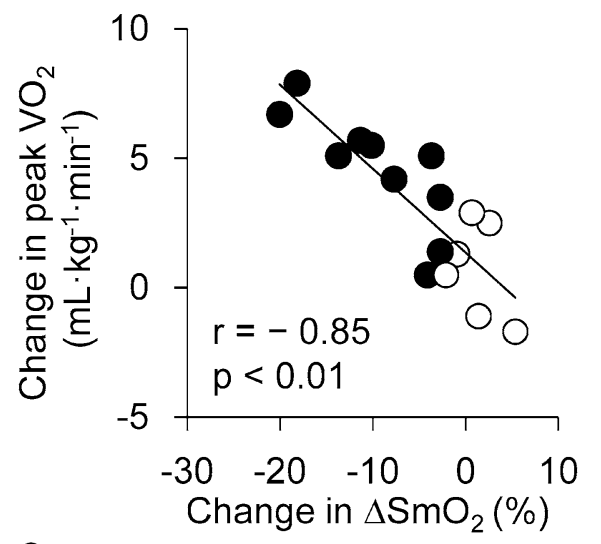

C

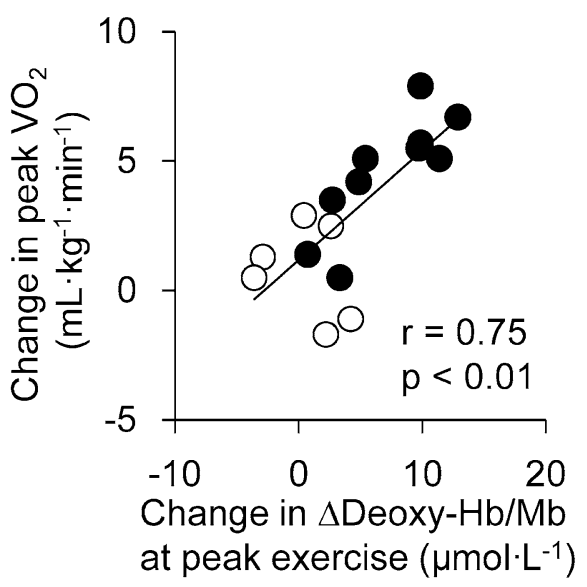

b

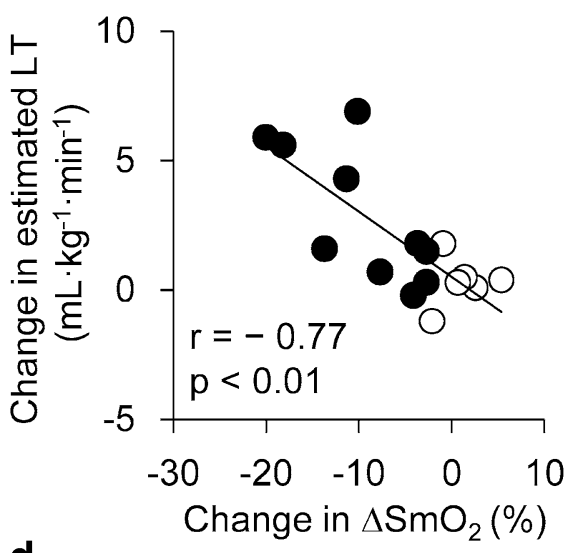

d

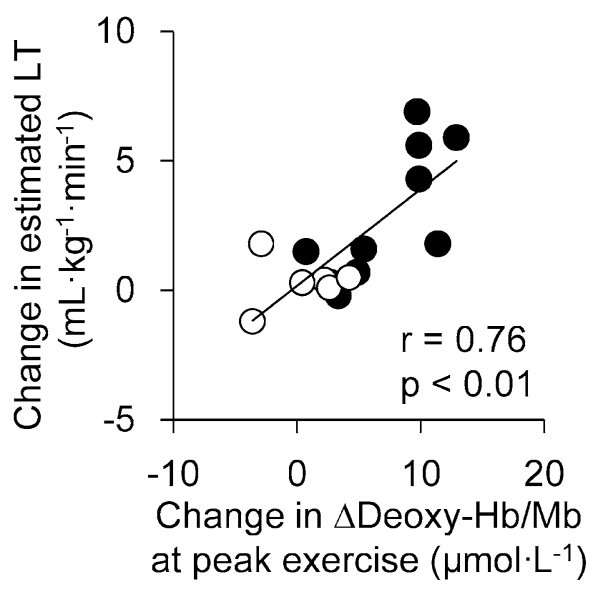

\section{Correlation analysis}

In all subjects (TR and $\mathrm{CON}$ ), significant negative relationships were observed between change in $\Delta \mathrm{SmO}_{2}$ by training and increase in peak $\mathrm{VO}_{2}(r=-0.85, p<0.01$; Fig. 4a) and estimated LT ( $r=-0.77, p<0.01$; Fig. $4 \mathrm{~b})$. Similarly, there were positive relationships between changes in $\Delta$ deoxy- $\mathrm{Hb} / \mathrm{Mb}$ at peak exercise by training and increase in peak $\mathrm{VO}_{2}(r=0.75, p<0.01$; Fig. $4 \mathrm{c})$ or increase in estimated LT ( $r=0.76, p<0.05$; Fig. $4 d$ ). In TR, change in $\Delta \mathrm{SmO}_{2}$ by training was also significantly negatively correlated with an increase in peak $\mathrm{VO}_{2}(r=-0.65, p<0.05)$ and estimated LT ( $r=-0.73, p<0.05)$. Similarly, significant positive relationships were observed between changes in $\Delta$ deoxy $-\mathrm{Hb} / \mathrm{Mb}$ at peak exercise by training and increase in peak $\mathrm{VO}_{2}(r=0.64, p<0.05)$ or estimated LT $(r=0.78$, $p<0.01$ ).

When the influence of light scattering on NIRS variables was not corrected, the relationship was robust. Changes in $\Delta \mathrm{SmO}_{2}$ without fat correction were significantly negatively correlated with an increase in peak $\mathrm{VO}_{2}(r=-0.62$, $p<0.05)$ and estimated LT $(r=-0.81, p<0.01)$. There were significant positive relationships between changes in
$\Delta$ deoxy- $\mathrm{Hb} / \mathrm{Mb}$ at peak exercise by training and enhancement of peak $\mathrm{VO}_{2}(r=0.70, p<0.01)$ or estimated LT $(r=0.83, p<0.01)$.

Workloads of training intensity (W) at end of training ( $r=0.57, p=0.08)$, improvement of training intensity $(r=0.71, p<0.05)$, and training frequency $(r=0.71$, $p<0.05)$ were related to the increase in peak $\mathrm{VO}_{2}$ by training.

\section{Discussion}

\section{Muscle deoxygenation}

After exercise training for 12 weeks in early post-MI patients, skeletal muscle deoxygenation during submaximal and peak exercise was enhanced, while no significant changes were observed in any variables in CON. Because deoxygenation also differed significantly at a given absolute power output, enhancement of deoxygenation is not solely attributed to the increase in maximal power output by training. Aerobic exercise training is confirmed to enhance deoxygenation measured by NIRS technique in 
healthy subjects (evaluated without a non-training group) (Kime et al. 2010; Prieur and Mucci 2013) and CHF patients (evaluated with a non-training group) (Mezzani et al. 2013). One possible explanation for the enhancement of muscle deoxygenation is the enhancement of muscle $\mathrm{O}_{2}$ consumption by aerobic training. Aerobic training increased oxidative enzyme activity in skeletal muscle of MI rats (Moreira et al. 2013). Belardinelli et al. (1995) reported that aerobic cycling training increased mitochondrial density at VL without improvement of cardiac output in CHF patients. In the present study, $\mathrm{SmO}_{2}$ was significantly lower and deoxy- $\mathrm{Hb} / \mathrm{Mb}$ was significantly higher after training compared to before training, while total- $\mathrm{Hb} /$ $\mathrm{Mb}$, which is an indicator of blood volume, was not significantly changed during exercise. Moreover, oxy- $\mathrm{Hb} / \mathrm{Mb}$ values were decreased after training, even though changes in oxy-Hb/Mb did not reach statistical significance. Although NIRS technique measured the muscle $\mathrm{O}_{2}$ balance between supply and utilization, muscle deoxygenation after training in MI may be partly explained by the increase in muscle $\mathrm{O}_{2}$ consumption of exercising muscle. Another possibility for enhanced muscle deoxygenation during submaximal exercise is reduced muscle blood flow caused by exercise training, as seen in previous studies of healthy subjects (Saito et al. 1980) and post-MI patients (Clausen and Trap-Jensen 1970). However, $\mathrm{VO}_{2}$ during submaximal exercise was significantly higher after training in this study (as described below). Due to the generally positive relationship between muscle blood flow and $\mathrm{VO}_{2}$, we suspect that a reduction in muscle blood flow results in higher $\mathrm{VO}_{2}$. Taken together, we presume that the enhancement of muscle deoxygenation can be most likely be explained by muscle $\mathrm{O}_{2}$ utilization change, rather than flow change, during submaximal exercise.

T1/2reoxy is an index of muscle oxidative capacity, and it also reflects the balance between muscle $\mathrm{O}_{2}$ supply and utilization. In this study, no significant changes were observed both in TR and CON. In contrast, in the TR group, peak $\mathrm{VO}_{2}$ was significantly increased after intervention. These results suggest that muscle $\mathrm{VO}_{2}$ after peak exercise was higher after intervention compared with before in $\mathrm{TR}$, and lead us to speculate that muscle blood flow at peak exercise is also increased by training. However, we should measure muscle blood flow directly in future studies.

\section{Muscle deoxygenation and aerobic capacity}

In early post-MI patients, the effects of aerobic training on peripheral factors and its relation to peak $\mathrm{VO}_{2}$ have not been established. Previous studies partly demonstrated that an aerobic training intervention affected a cross-sectional area of thigh muscle (Murabayashi et al. 1997) and muscle oxidative capacity by nuclear magnetic resonance spectroscopy (Cottin et al. 1996), and the changes were related to peak $\mathrm{VO}_{2}$ in early post-MI patients. However, these studies did not have a non-training control group. In the TR group of the present study, changes in $\Delta \mathrm{SmO}_{2}$ and $\Delta$ deoxy-Hb were significantly correlated with changes in peak $\mathrm{VO}_{2}$ and estimated LT, while no significant difference was observed in either cardiovascular or muscle deoxygenation variables in CON. An increase in aerobic capacity reduces cardiovascular-associated morbidity and mortality (Merz et al. 2009). Therefore, our findings partly support the idea that exercise training may be important for early post-MI patients to improve peripheral functions and aerobic capacity.

$\mathrm{VO}_{2}$ is the product of cardiac output (convective $\mathrm{O}_{2}$ supply) and $\mathrm{O}_{2}$ extraction, and in a strict sense, muscle $\mathrm{O}_{2}$ extraction can be estimated by deoxy- $\mathrm{Hb} / \mathrm{Mb}$ or $\mathrm{SmO}_{2}$ when total-Hb/Mb is stable (Ferrari et al. 1997). In this study, total- $\mathrm{Hb} / \mathrm{Mb}$ increased as power output increased, however, total- $\mathrm{Hb} / \mathrm{Mb}$ was not different between before and after 12 weeks of intervention. Therefore, the change in deoxy- $\mathrm{Hb} / \mathrm{Mb}$ and $\mathrm{SmO}_{2}$ between before and after training may be partly explained by increasing muscle $\mathrm{O}_{2}$ extraction. Okita et al. (2013) suggested that skeletal muscle dysfunction, rather than cardiac dysfunction, limits exercise tolerance in most patients with CHF. Hence, the strong relationship between change in muscle deoxygenation and increase in peak aerobic capacity in the present study may be attributed to the idea that increasing peak aerobic capacity was mainly caused by increasing muscle $\mathrm{O}_{2}$ extraction, rather than cardiac output, during training in early post-MI patients.

\section{Cardiorespiratory variables}

$\mathrm{VO}_{2}$ responses

The longer MRT may be caused by low muscle $\mathrm{O}_{2}$ supply or muscle oxidative capacity (Meyer et al. 1998), and partly results in lower $\mathrm{VO}_{2}$ at a given absolute power output (Takagi et al. 2014). In this study, although the longer MRT at baseline was similar to heart disease patients in previous studies (Meyer et al. 1998; Takagi et al. 2014), the 12 weeks of training decreased MRT and increased $\mathrm{VO}_{2}$. In fact, previous results demonstrated that, after 6 months of exercise training, leg $\mathrm{VO}_{2}$ at a given absolute WR was increased in CHF patients (Hambrecht et al. 1995). Higher $\mathrm{VO}_{2}$ after training can be interpreted to mean that cycling efficiency was reduced and/or the contribution of oxidative metabolism was increased (i.e. reduction in contribution of phosphocreatine breakdown and/or glycolysis) (Meyer et al. 1998; Poole et al. 2012; Rossiter 2011; Takagi et al. 2014). However, it seems that the lower $\mathrm{VO}_{2}$ before training should not be assumed to be related to higher cycling 
efficiency in heart disease patients (Poole et al. 2012; Rossiter 2011). Taken together, from the results of the previous studies, aerobic training may increase muscle $\mathrm{O}_{2}$ supply and/or muscle oxidative capacity and, consequently, increased contribution of oxidative metabolism in early post-MI patients in this study. However, future studies are needed with a greater number of subjects.

\section{$\mathrm{HR}$ and $\mathrm{O}_{2}$ pulse responses}

Lower submaximal HR after TR in this study was a common adaptation of TR, as well as in previous reports of early post-MI patients (Dressendorfer et al. 1995). $\mathrm{O}_{2}$ pulse was increased by exercise training, as seen in a previous study of early post-MI patients (Giallauria et al. 2012). Though $\mathrm{O}_{2}$ pulse is the product of stroke volume multiplied by arteriovenous $\mathrm{O}_{2}$ difference, increased $\mathrm{O}_{2}$ pulse with a reduction in HR may lead us to speculate that stroke volume would possibly be increased by training.

\section{Influence of intensity and frequency of training}

In the present study, training intensity in last session and training frequency were positively related to improvement of peak aerobic capacity. Moreover, peak $\mathrm{VO}_{2}$ was certainly improved by aerobic training in TR, even though both the training intensity and the frequency are low. These results indicated that both training intensity and frequency are important factors in improving peak aerobic capacity in early post-MI. Recent previous studies demonstrated that high-intensity interval training may be effective to improve aerobic capacity in coronary heart disease patients (Rognmo et al. 2012), and the risk may be the same compared with moderate intensity aerobic training in heart failure patients (Wisløff et al. 2007). However, Blumenthal et al. (1988) pointed out that "many patients experience subjective discomfort during exercise at high intensity and are therefore dissuaded from pursuing further training, despite its potential benefits". Moreover, to our knowledge, a risk of high-intensity interval training is unknown in early postMI patients. Therefore, we presume that frequent aerobic training seems to be one of the best options to improve aerobic capacity in early post-MI patients for now, even if the benefits are not ideal.

\section{Study limitations}

We recognize the absence of direct measurement, such as muscle blood flow, cardiac output during exercise, or muscle biopsy, to support our findings. Secondarily, the number of subjects is quite low, especially women. Our findings should be confirmed in a larger group of subjects. Moreover, the subjects in this study were not divided randomly into TR or CON. Thus, some sampling bias cannot be ruled out. In addition, our subjects included patients treated with medications. However, our findings cannot be solely attributed to these medications, because the dosages remained stable throughout the study. Furthermore, there are some general limitations of NIRS technique (Hamaoka et al. 2007). NIRS data reflects tissue oxygenation in arterioles, capillaries, and venules of localized exercising muscle, especially in the superficial region of the muscle. The deoxygenation measured by NIRS was heterogeneous between muscles and also within a single muscle (Takagi et al. 2013). Hence, the muscle deoxygenation in early post-MI patients may be restricted to the superficial region of the distal site of the VL muscle. Because muscle recruitment affects the changes in NIRS variables during ramp cycling exercise (Chin et al. 2011), it may be that central attenuation or inhibition of muscle activity in the superficial region of the distal site of the VL muscle is responsible for the changes observed in NIRS dynamics. In particular, post-MI patients in this study had substantially preserved LVEF even before training, and the effect of training on deoxygenation may be influenced by the previously preserved LVEF. Furthermore, in early post-MI patients, aerobic capacity may be increased by very light intensity exercise such as physical activity (Dressendorfer et al. 1995). Though none of the subjects in CON were involved in training over the 12 weeks, we did not regulate their usual physical activity. Future studies are needed which include measurement of physical activity.

\section{Conclusions}

Aerobic exercise training enhanced skeletal muscle deoxygenation during exercise in early post-MI patients. Moreover, the enhancement of muscle deoxygenation by aerobic exercise training may be related to an increase in aerobic capacity in early post-MI patients.

Acknowledgments The authors are grateful for revision of this manuscript by Andrea Hope. We also thank Tsubasa Watanabe, Miwako Tanabe, Yuki Takahashi, Chie Hamanaka, Tae Minegishi, and Toshimichi Nakazawa for their helpful technical assistance.

\section{Compliance with ethical standards}

Conflict of interest The authors declare that they have no conflict of interest.

Funding This study was supported by a Grant-in-Aid for scientific research from the Japan Society for the Promotion of Science (Grant Number 26882044).

Ethical approval All procedures performed in studies involving human participants were in accordance with the ethical standards of the institutional research committee and with the 1964 Helsinki declaration and its later amendments or comparable ethical standards. 
Informed consent Informed consent was obtained from all individual participants included in the study.

Open Access This article is distributed under the terms of the Creative Commons Attribution 4.0 International License (http://creativecommons.org/licenses/by/4.0/), which permits unrestricted use, distribution, and reproduction in any medium, provided you give appropriate credit to the original author(s) and the source, provide a link to the Creative Commons license, and indicate if changes were made.

\section{References}

Beaver WL, Wasserman K, Whipp BJ (1986) A new method for detecting anaerobic threshold by gas exchange. J Appl Physiol 60(6):2020-2027

Belardinelli R, Georgiou D, Scocco V, Barstow TJ, Purcaro A et al (1995) Low intensity exercise training in patients with chronic heart failure. J Am Coll Cardiol 26(4):975-982. doi:10.1016/0735-1097(95)00267-1

Blumenthal JA, Rejeski WJ, Walsh-Riddle M, Emery CF, Miller H, Roark S, Ribisl PM, Morris PB, Brubaker P, Williams RS (1988) Comparison of high- and low-intensity exercise training early after acute myocardial infarction. Am J Cardiol 61(1):26-30. doi:10.1016/0002-9149(88)91298-2

Boone J, Koppo K, Bouckaert J (2008) The VO2 response to submaximal ramp cycle exercise: influence of ramp slope and training status. Respir Physiol Neurobiol 161(3):291-297. doi:10.1016/j. resp.2008.03.008

Chin LM, Kowalchuk JM, Barstow TJ, Kondo N, Amano T, Shiojiri $\mathrm{T}$, Koga S (2011) The relationship between muscle deoxygenation and activation in different muscles of the quadriceps during cycle ramp exercise. J Appl Physiol (1985) 111(5):1259-1265. doi:10.1152/japplphysiol.01216.2010

Clausen JP, Trap-Jensen J (1970) Effects of training on the distribution of cardiac output in patients with coronary artery disease. Circulation 42(4):611-624. doi:10.1161/01.CIR.42.4.611

Cottin Y, Walker P, Rouhier-Marcer I, Cohen M, Louis P, Didier JP, Casillas JM, Wolf JE, Brunotte F (1996) Relationship between increased peak oxygen uptake and modifications in skeletal muscle metabolism following rehabilitation after myocardial infarction. J Cardiopulm Rehabil 16(3):169-174

Day JR, Rossiter HB, Coats EM, Skasick A, Whipp BJ (2003) The maximally attainable VO2 during exercise in humans: the peak vs. maximum issue. J Appl Physiol 95(5):1901-1907. doi:10.1152/japplphysiol.00024.2003

Dressendorfer RH, Franklin BA, Cameron JL, Trahan KJ, Gordon S, Timmis GC (1995) Exercise training frequency in early post-infarction cardiac rehabilitation. Influence on aerobic conditioning. J Cardiopulm Rehabil 15(4):269-276. doi:10.1097/00008483-199507000-00003

Dubach P, Myers J, Dziekan G, Goebbels U, Reinhart W, Muller P, Buser P, Stulz P, Vogt P, Ratti R (1997) Effect of high intensity exercise training on central hemodynamic responses to exercise in men with reduced left ventricular function. J Am Coll Cardiol 29(7):1591-1598. doi:10.1016/S0735-1097(97)82540-5

Ferrari M, Binzoni T, Quaresima V (1997) Oxidative metabolism in muscle. Philos Trans R Soc Lond B Biol Sci 352(1354):677683. doi:10.1098/rstb.1997.0049

Giallauria F, Acampa W, Ricci F, Vitelli A, Maresca L, Mancini M, Grieco A, Gallicchio R, Xhoxhi E, Spinelli L, Cuocolo A, Vigorito C (2012) Effects of exercise training started within 2 weeks after acute myocardial infarction on myocardial perfusion and left ventricular function: a gated SPECT imaging study. Eur J Prev Cardiol 19(6):1410-1419. doi:10.1177/1741826711425427

Hamaoka T, McCully KK, Quaresima V, Yamamoto K, Chance B (2007) Near-infrared spectroscopy/imaging for monitoring muscle oxygenation and oxidative metabolism in healthy and diseased humans. J Biomed Opt 12(6):062105. doi:10.1117/1.2805437

Hambrecht R, Niebauer J, Fiehn E, Kälberer B, Offner B, Hauer K, Riede U, Schlierf G, Kübler W, Schuler G (1995) Physical training in patients with stable chronic heart failure: effects on cardiorespiratory fitness and ultrastructural abnormalities of leg muscles. J Am Coll Cardiol 25(6):1239-1249. doi:10.1016/0735-1097(94)00568-B

Ichimura S, Murase N, Osada T, Kime R, Homma $\mathrm{T}$, Ueda $\mathrm{C}$, Nagasawa T, Motobe M, Hamaoka T, Katsumura T (2006) Age and activity status affect muscle reoxygenation time after maximal cycling exercise. Med Sci Sports Exerc 38(7):1277-1281. doi:10.1249/01.mss.0000227312.08599.f1

Johnson DA, Sacrinty MT, Gomadam PS, Mehta HJ, Brady MM, Douglas CJ, Paladenech CC, Robinson KC (2014) Effect of early enrollment on outcomes in cardiac rehabilitation. Am J Cardiol 114(12):1908-1911. doi:10.1016/j.amjcard.2014.09.036

Kime R, Niwayama M, Fujioka M, Shiroishi K, Osawa T, Shimomura K, Osada T, Murase N, Katsumura T (2010) Unchanged muscle deoxygenation heterogeneity during bicycle exercise after 6 weeks of endurance training. Adv Exp Med Biol 662:353-358. doi:10.1007/978-1-4419-1241-1_51

Merz CNB, Alberts MJ, Balady GJ, Ballantyne CM, Berra K, Black HR, Blumenthal RS, Davidson MH, Fazio SB, Ferdinand KC, Fine LJ, Fonseca V, Franklin BA, McBride PE, Mensah GA, Merli GJ, O'Gara PT, Thompson PD, Underberg JA (2009) ACCF/AHA/ACP 2009 competence and training statement: a curriculum on prevention of cardiovascular disease: a report of the American College of Cardiology Foundation/American Heart Association/American College of Physicians Task Force on Competence and Training (Writing Committee to Develop a Competence and Training Statement on Prevention of Cardiovascular Disease). Circulation 120(13):e100-e126. doi:10.1161/ CIRCULATIONAHA.109.192640

Meyer K, Schwaibold M, Hajric R, Westbrook S, Ebfeld D, Leyk D, Roskamm H (1998) Delayed VO2 kinetics during ramp exercise: a criterion for cardiopulmonary exercise capacity in chronic heart failure. Med Sci Sports Exerc 30(5):643-648

Mezzani A, Grassi B, Jones AM, Giordano A, Corrà U, Porcelli S, Della Bella S, Taddeo A, Giannuzzi P (2013) Speeding of pulmonary $\mathrm{VO}_{2}$ on-kinetics by light-to-moderate-intensity aerobic exercise training in chronic heart failure: clinical and pathophysiological correlates. Int J Cardiol 167(5):2189-2195. doi:10.1016/j.ijcard.2012.05.124

Minotti JR, Johnson EC, Hudson TL, Zuroske G, Murata G, Fukushima E, Cagle TG, Chick TW, Massie BM, Icenogle MV (1990) Skeletal muscle response to exercise training in congestive heart failure. J Clin Invest 86(3):751-758. doi:10.1172/JCI114771

Moreira JB, Bechara LR, Bozi LH, Jannig PR, Monteiro AW, Dourado PM, Wisløff U, Brum PC (2013) High- versus moderateintensity aerobic exercise training effects on skeletal muscle of infarcted rats. J Appl Physiol (1985) 114(8):1029-1041. doi:10.1152/japplphysiol.00760.2012

Murabayashi T, Itoh H, Kato M, Tanabe K, Kato K (1997) Mechanism of increase in exercise tolerance in patients with acute myocardial infarction. J Cardiol 30(5):241-249

Myers J, Kaykha A, George S, Abella J, Zaheer N, Lear S, Yamazaki T, Froelicher V (2004) Fitness versus physical activity patterns in predicting mortality in men. Am J Med 117(12):912-918. doi:10.1016/j.amjmed.2004.06.047 
Niwayama M, Lin L, Shao J, Kudo N, Yamamoto K (2000) Quantitative measurement of muscle hemoglobin oxygenation using near-infrared spectroscopy with correction for the influence of a subcutaneous fat layer. Rev Sci Instrum 71:4571-4575. doi: $10.1063 / 1.1322578$

Niwayama M, Sono S, Murata H, Yoshida H, Shinohara S (2007) Errors in muscle oxygenation measurement using spatiallyresolved NIRS and its correction. J Jpn Coll Angiol 47(1):17-20

Okita K, Kinugawa S, Tsutsui H (2013) Exercise intolerance in chronic heart failure - skeletal muscle dysfunction and potential therapies. Circ J 77(2):293-300. doi:http://doi.org/10.1253/circj. CJ-12-1235

Poole DC, Hirai DM, Copp SW, Musch TI (2012) Muscle oxygen transport and utilization in heart failure: implications for exercise (in)tolerance. Am J Physiol Heart Circ Physiol 302(5):H1050H1063. doi:10.1152/ajpheart.00943.2011

Prieur F, Mucci P (2013) Effect of high-intensity interval training on the profile of muscle deoxygenation heterogeneity during incremental exercise. Eur J Appl Physiol 113(1):249-257. doi:10.1007/s00421-012-2430-9

Rognmo Ø, Moholdt T, Bakken H, Hole T, Mølstad P, Myhr NE, Grimsmo J, Wisløff U (2012) Cardiovascular risk of high- versus moderate-intensity aerobic exercise in coronary heart disease patients. Circulation 126(12):1436-1440. doi:10.1161/ CIRCULATIONAHA.112.123117

Rossiter HB (2011) Exercise: kinetic considerations for gas exchange. Compr Physiol 1(1):203-244. doi:10.1002/cphy.c090010

Saito M, Matsui H, Miyamura M (1980) Effects of physical training on the calf and thigh blood flows. Jpn J Physiol 30(6):955-959. doi:10.2170/jjphysiol.30.955
Sullivan MJ, Higginbotham MB, Cobb FR (1988) Exercise training in patients with severe left ventricular dysfunction. Hemodynamic and metabolic effects. Circulation 78(3):506-515

Takagi S, Kime R, Niwayama M, Murase N, Katsumura T (2013) Muscle oxygen saturation heterogeneity among leg muscles during ramp exercise. Adv Exp Med Biol 765:273-278. doi:10.1007/978-1-4614-4989-8_38

Takagi S, Murase N, Kime R, Niwayama M, Osada T, Katsumura T (2014) Skeletal muscle deoxygenation abnormalities in early post myocardial infarction. Med Sci Sports Exerc 46(11):20622069. doi:10.1249/MSS.0000000000000334

Wasserman K, Whipp BJ, Koyl SN, Beaver WL (1973) Anaerobic threshold and respiratory gas exchange during exercise. J Appl Physiol 35(2):236-243

Wisløff U, Støylen A, Loennechen JP, Bruvold M, Rognmo Ø, Haram PM, Tjønna AE, Helgerud J, Slørdahl SA, Lee SJ, Videm V, Bye A, Smith GL, Najjar SM, Ellingsen Ø, Skjaerpe T (2007) Superior cardiovascular effect of aerobic interval training versus moderate continuous training in heart failure patients: a randomized study. Circulation 115(24):3086-3094. doi:10.1161/ CIRCULATIONAHA.106.675041

Wohl AJ, Lewis HR, Campbell W, Karlsson E, Willerson JT, Mullins CB, Blomqvist CG (1977) Cardiovascular function during early recovery from acute myocardial infarction. Circulation 56(6):931-937. doi:10.1161/01.CIR.56.6.931 